\section{Colonatos e}

\section{aldeamentos}

no Niassa,

Moçambique:

\section{processos e}

impactos

sociais em tempo

de guerra

(1964-1974)

\section{Cláudia Castelo $[*, * *]$}

[*] Instituto de Ciências Sociais/Universidade de Lisboa (ICS/ULisboa). Lisboa, Portugal. claudia.castelo@ics.ulisboa.pt.

[**] A pesquisa para o artigo foi cofinanciada pelo Fundo Europeu de Desenvolvimento Regional (Feder), por meio do Programa Operacional Competitividade e Internacionalização (Compete) 2020, e pela Fundação para a Ciência e a Tecnologia, no âmbito do projeto "Os mundos do (sub)desenvolvimento: processos e legados do império colonial português em perspectiva comparada (1945-1975)", Centro de Estudos Sociais/Universidade de Coimbra.

ORCID: https://orcid.org/0000-0001-7403-4404
Resumo: $\mathrm{O}$ artigo analisa dois processos concomitantes: a con centração de populações Ajaua (Yao) e Nianja em aldeamentos e a criação de colonatos para portugueses no distrito do Niassa, Moçambique, como resposta do Estado português à luta de libertação nacional encetada pela Frelimo (Frente de Libertação de Moçambique) em setembro de 1964. Ambos os processos articulam a questão da segurança e da soberania do ponto de vista português com a questão do desenvolvimento colonial, equacionado em termos de crescimento económico e de "promoção social". Depois de se dar conta da genealogia destes processos, aborda-se a sua tradução no Niassa, caracterizando-se as populações envolvidas e discutindo-se os impactos sociais nas suas condições de vida. Conclui-se que nem os aldeamentos nem os colonatos conseguiram cumprir a promessa de promoção social nem criaram comunidades enraizadas e estáveis; foram antes a causa de perturbação social e conflito.

Palavras-chave: Aldeamentos; Colonatos; Guerra colonial.

Rural settlements and protected villages in Niassa, Mozambique: processes and social impacts in wartime (1964-1974)

\begin{abstract}
The article analyses two parallel processes: the villagization of local populations (Yao and Nyanja) and the rural settlement of Portuguese from the metropole (mainly Madeira and Azores islands) in the Niassa district, Mozambique, as a response of the colonial state to the liberation struggle initiated by Frelimo (the Mozambican Liberation Front) in September 1964. Both processes combine Portuguese national security and sovereignty with colonial development, envisioned as economic growth and social promotion. After addressing the genealogy of these processes, I will zoom in its translation in Niassa, characterize the populations involved and discuss the social impacts in their living conditions. I conclude that the protected villages and the rural settlements did not bring social promotion to the populations nor were able to create rooted and stable communities; instead were the cause of social disruption and conflict.
\end{abstract} Keywords: Protected villages; Rural settlements; Colonial war. 


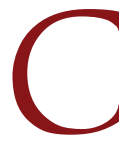

om este artigo pretendo analisar dois processos concomitantes: a criação de colonatos ou núcleos de povoamento agrário para portugueses da metrópole (Portugal) e a concentração forçada de populações rurais africanas em aldeamentos no distrito do Niassa, situado no extremo noroeste de Moçambique, fazendo fronteira a norte com o Tanganica (Tanzânia) e a oeste com a Niassalândia (Malawi). Os dois processos ocorreram durante a fase final da dominação colonial portuguesa e obedeceram a uma cronologia muito aproximada: o colonato de Nova Madeira teve início em dezembro de 1963 e os aldeamentos em 1966. Foram uma resposta do Estado português à contestação anticolonial e à luta de libertação nacional encetada pela Frelimo (Frente de Libertação de Moçambique) em setembro de 1964. Ambos os processos articularam a questão da segurança e da soberania portuguesa (a permanência de Portugal em África) com a questão do desenvolvimento colonial, equacionado em termos de crescimento económico e de "promoção social" das populações rurais alvo das intervenções, quer de origem europeia quer africana.

A pesquisa empírica foi feita em fontes primárias muito diversas, a saber: documentação de arquivo produzida por organismos do poder colonial, como administração civil, serviços técnicos, missão científica, polícia política, serviço de informações, forças armadas, ${ }^{1}$ publicações de pendor técnico e científico coevas elaboradas por especialistas portugueses e estrangeiros; imprensa; memórias de indivíduos que testemunharam em primeira mão os processos analisados, como um elemento da Frelimo, um missionário anglicano e dois militares portugueses. Houve a preocupação de cruzar essas fontes, de natureza e proveniência variada, analisá-las e interpretá-las à luz da mais recente bibliografia sobre contrassubversão e políticas de desenvolvimento rural no colonialismo tardio. O texto está estruturado em três partes: na primeira, enquadra-se brevemente os processos de povoamento agrário e ordenamento e controlo populacional numa genealogia mais ampla; na segunda, faz-se um zoom in à sua tradução no Niassa; e, na última, procura-se discutir os impactos sociais de colonatos e aldeamentos, em particular no modo de vida e no quotidiano dos sujeitos envolvidos.

\section{Antecedentes}

Tanto os colonatos como os aldeamentos no Niassa corporizam numa escala espácio-temporal menor dois processos mais amplos: a colonização branca e a concentração de

\footnotetext{
${ }^{1}$ A consulta realizou-se em quatro instituições portuguesas: Arquivo da Defesa Nacional - ADN (Paço de Arcos), Arquivo Histórico Ultramarino - AHU, Arquivo Nacional da Torre do Tombo - ANTT e no Arquivo e Centro de Documentação e Informação do Instituto de Investigação Científica Tropical - AIICT e CDI-IICT, ambos à guarda da Universidade de Lisboa - UL (Lisboa).
} 
populações africanas idealizadas e/ou levadas a cabo no âmbito de políticas de engenharia social nos meios rurais de Angola, desde finais do século XIX, e de Moçambique, desde o período entreguerras.

No que respeita à gestão das populações rurais africanas, o debate em fóruns coloniais sobre a fixação dos nativos em "aldeamentos indígenas", como meio de fomento colonial, e as iniciativas conduzidas em Moçambique e Angola, nas décadas de 1920 a 1940, foram analisados por Coelho (1993), Direito (2013 e 2014) e Coghe (2014 e 2016). Esses autores detêm-se, nomeadamente, no projeto de decreto sobre a "organização social e económica das populações indígenas", elaborado pelo ministro das Colónias Francisco José Vieira Machado, em 1939, discutido e aprovado com alterações pelo Conselho Superior do Império Colonial e pela Câmara Corporativa, e que nunca chegou a ser promulgado (Coelho, 1993, p. 120-122; Direito, 2013, p. 783-785; Coghe, 2014, p. 239-240). Jerónimo e Dores (2017, p. 191-204) aprofundaram a análise do projeto, do parecer do Conselho Superior do Império e desenvolvimentos posteriores e mostram que se pretendeu colocar os aldeamentos sob a tutela da Igreja católica e dos missionários, argumentando uma genealogia com as "experiências históricas" - como Teófilo Duarte referia - ensaiadas no Brasil pelos jesuítas no século XVI. Em traços gerais, e não obstante diferenças locais, os objetivos da fixação das populações rurais africanas eram contrariar a dispersão, o êxodo para os centros urbanos e a proletarização, e contribuir para a constituição de uma classe de pequenos proprietários rurais africanos, para o aumento da produção agrícola mediante práticas agrícolas mais modernas (em vez da agricultura itinerante e de autossubsistência), e para a monetarização da sua economia, em suma, promover aquilo que se considerava ser a "civilização" e o progresso material e social dos camponeses africanos. Políticas de reordenamento rural também foram conduzidas no Congo Belga, na África do Sul e em colónias britânicas e francesas em cronologias próximas, numa óptica de governabilidade modernizadora e recorrendo a conhecimento social aplicado (Jerónimo e Dores, 2017, p. 184-185).²

Durante as guerras coloniais/de libertação nas colónias portuguesas, a concentração das populações colonizadas foi levada mais longe em termos quantitativos e coercivos. Em conjunto com os aspectos militares e de intelligence, e a ação psicológica, constituiu um elemento fundamental da estratégia de contrassubversão portuguesa em Moçambique (Coelho, 1993, p. 203). Em termos doutrinários não constituiu novidade, pois seguia modelos de reassentamento forçado em aldeias estratégicas já implementados noutros contextos de guerra de guerrilha anticolonial. Por exemplo, e para referir apenas casos em África, no Quénia,

${ }^{2}$ Benoît D’Estoile (2017) mostrou como George Balandier esteve profundamente envolvido na produção de uma ciência social aplicada à elaboração de um programa de estabilização de populações da África Oriental Francesa, tendo em vista potenciar o seu desenvolvimento económico e social. 
após a Revolta Mau-Mau em 1952 contra o domínio britânico, e na Argélia, onde a luta armada contra o colonialismo francês havia começado em 1954. Moritz Feichtinger (2017), que estudou comparativamente esses dois casos, mostra que a violência em massa relacionada com a remoção forçada das populações e o seu confinamento nos novos espaços controlados foi um meio de implementar as políticas de desenvolvimento ou modernização no período tardo-colonial. Os aldeamentos em Moçambique e Angola inserem-se na mesma lógica e ideologia, são variantes do mesmo fenómeno global de articulação de planeamento e engenharia social e contrassubversão. Até ao momento, só o caso dos aldeamentos criados no distrito de Tete (Moçambique), no contexto do início da luta armada da Frelimo contra o domínio português e da ameaça à megaobra em curso de construção da barragem de Cahora Bassa, foi estudado em profundidade (Coelho, 1989 e 1993).

Por seu turno, as políticas de povoamento branco de Angola e Moçambique destinadas a fixar população metropolitana no interior rural daquelas colónias respondiam ao desejo de ocupar o território (para além dos centros urbanos, onde a maioria dos colonos residia) com elementos "civilizadores". ${ }^{3}$ O povoamento com gente da metrópole era apresentado e visto como um meio de nacionalizar os territórios e promover o seu desenvolvimento económico e social. Nos anos de 1950-1960, registou-se um investimento estatal sem precedentes em colonatos e no transporte desde a metrópole e fixação em Angola e Moçambique de colonos portugueses oriundos dos meios rurais do continente e das ilhas da Madeira e dos Açores. Os diversos planos de fomento destinavam verbas significativas à rubrica "povoamento" (estudos, projetos e realizações de obras destinadas ao povoamento, transporte e instalação de colonos, assistência técnica e financeira). O Conselho Superior de Fomento Ultramarino, a Junta de Emigração e mais tarde a Repartição de Povoamento e Assuntos Demográficos, da Direção-geral de Economia do Ministério do Ultramar, encarregaram-se da seleção dos colonos, que, no destino, ficavam enquadrados e sob tutela estatal. Só após o pagamento de todas as amortizações ao Estado, os colonos poderiam vir a ser proprietários de pleno direito dos terrenos, casas, alfaias etc. inicialmente concedidos.

Os colonatos modelo da Cela, no distrito do Quanza-Sul em Angola, e do Limpopo, no sul de Moçambique, implicaram a expropriação de terrenos, o arrasamento do habitat preexistente e o reassentamento das populações autóctones (Castelo, 2016). Os colonos portugueses ficavam com as melhores terras já beneficiadas pelos sistemas de irrigação e os antigos ocupantes eram remetidos para terras de sequeiro e menos férteis. A maioria dos africanos, ante a dificuldade de assegurar o sustento familiar e pagar os impostos, via-se na contingência de trabalhar para os brancos.

${ }^{3}$ Sobre a fixação de portugueses da metrópole em Angola e Moçambique desde as primeiras décadas do século XX até 1974, ver Castelo (2007). 
A construção do colonato da Cela destinava-se exclusivamente a colonos metropolitanos. Estes, inicialmente, foram impedidos de recrutar mão de obra africana, devendo o agregado familiar ser autossuficiente nas tarefas agrícolas. Já nos colonatos do Limpopo e do Cunene (sul de Angola) foi prevista a integração de famílias autóctones, para dar mostras da capacidade portuguesa de criar sociedades multirraciais em África. Mas essa integração foi muito desigual. Em 1957, os autóctones abrangidos pelo empreendimento no Limpopo apenas tiveram acesso à fruição de glebas de dois hectares. A partir de 1959, a um número reduzido de africanos assimilados foi concedido casal agrícola de dimensões próximas aos atribuídos aos colonos brancos (4-10ha). ${ }^{4}$

A ocupação de terras por portugueses que se fixaram nas colónias fora dos esquemas de colonização oficial também envolveu frequentemente o esbulho de terras aos autóctones, sendo essa questão particularmente sensível e motivo de tensão e contestação. ${ }^{5}$ No Quénia, a expulsão de ocupantes Kikuyu das terras agrícolas na zona do monte Kenya por agricultores europeus e a crescente densidade populacional e desespero das massas Kikuyu sem terra na reserva foi o principal catalisador do surto da revolta Mau Mau (Feichtinger, 2017, p. 51). A situação foi à época analisada pelo então professor do Colégio de França e da Universidade Livre de Bruxelas, Pierre Gourou (1954), especialista de geografia das regiões tropicais. Raquel Soeiro de Brito (Elvas, 1925), geógrafa, professora do Instituto Superior de Ciências Sociais e Política Ultramarina e adjunta do chefe da Missão de Geografia Física e Humana do Ultramar Português, em informação para o chefe da Missão, e que este enviou à presidência da Comissão Executiva da Junta de Investigações do Ultramar, recomendava a leitura do artigo de Gourou, como alerta face a problemas com contornos idênticos que poderiam surgir nas colónias portuguesas. ${ }^{6}$

\section{Colonatos e aldeamentos no Niassa}

\footnotetext{
${ }^{4}$ Sobre a integração de famílias autóctones no colonato do Limpopo, ver Matine (2015). O autor esclarece que seriam assimilados de "fato" e não de "direito", isto é, indivíduos que falavam a língua portuguesa, sustentavam a família a seu cargo graças ao exercício de uma atividade remunerada e comportavam-se segundo os hábitos e costumes dos cidadãos portugueses, mesmo que não tivessem oficialmente deixado a condição de "indígenas" e adquirido a cidadania, de acordo com o estipulado no Estatuto dos Indígenas Portugueses das Províncias da Guiné, Angola e Moçambique, de 1954 (Matine, 2015, p. 65).

${ }^{5}$ Para a compreensão da dimensão histórica do fenómeno de expropriação de terras em Moçambique, ver Zamparoni ( [2007] 2012, p. 79-103).

${ }^{6}$ AllCT, Proc. 84 - Maria Raquel Soeiro de Brito. Informação relativa à criação de gado e pastoreio nos distritos de Moçâmedes e Huíla [Angola], anexa ao ofício de Orlando Ribeiro para o presidente da Comissão Executiva da Junta de Investigações do Ultramar, Lisboa, 2 dez. 1968, fl. 6.
} 
Antes de nos debruçarmos sobre os colonatos e aldeamentos criados no distrito do Niassa, importa salientar que a região foi administrada por uma companhia majestática entre 1890 e 1929.7 Da década de 1930 em diante esteve sob administração direta do Estado português. Porém, permaneceu uma região muito periférica do império colonial português e mesmo da colónia de Moçambique, nomeadamente devido à enorme distância da capital, Lourenço Marques (hoje, Maputo). A presença administrativa, militar e comercial portuguesa era muito débil. Em 1960, um território com uma área de 120.135 km² tinha a densidade populacional mais baixa da colónia (2,3 hab./ $\left.\mathrm{km}^{2}\right)$, sendo habitado por 281.083 indivíduos: 279.773 “negros”, 922 “brancos”, 139 “indianos” e 249 “mistos” (Moçambique, 1965, p. 43). Mesmo na sede do distrito, a população branca era diminuta: 309 europeus. O grau de desenvolvimento económico do distrito era muito incipiente. As vias de comunicação com o litoral e no interior do distrito eram escassas e faltavam infraestruturas públicas básicas. A falta de oferta escolar era notória, sendo suprida parcialmente pelos missionários anglicanos, que dispunham também de um hospital. ${ }^{8}$ A assistência religiosa anglicana, com uma missão a funcionar em Messumba desde 1882, estava mais enraizada do que a católica. A diocese do Niassa só iniciou funções a 6 de setembro de 1964. Em 1964, a Junta de Investigações do Ultramar publicou o livro de Nuno Beja Valdez dos Santos, O desconhecido Niassa. O desconhecimento das realidades locais e a fragilidade da ocupação colonial andavam a par e traduziam-se numa sensação de um certo abandono (p.e., Nogueira, 1995).

Em 1960, 17 países africanos conquistaram a independência. Ao redor do Niassa, nas colónias britânicas vizinhas, alastrava a contestação e a agitação anticolonial. O Tanganica tornou-se independente em dezembro de 1961. Entre as autoridades sentia-se a urgência de povoar o distrito com população europeia para que esta concorresse para a "civilização" da região e para a dinamização da economia e assim se atraíssem mais colonos e contrariasse a migração das populações autóctones para os territórios vizinhos, num processo de desenvolvimento em bola de neve, que garantisse a perpetuação do domínio português. Multiplicaram-se as vozes exaltando as potencialidades da região para o povoamento europeu, fazendo referência ao clima e à aptidão agrícola dos solos para a policultura de géneros alimentares.

\footnotetext{
${ }^{7}$ Sobre esse período, ver Medeiros (1997, p. 139-186).

${ }^{8}$ De acordo com John Paul (1975, p. 29-30) a escola da Missão de Messumba era a única completa em toda a região, embora só o curso primário que ministrava estivesse oficialmente reconhecido pelo governo português; o secundário não estava. Havia uma pequena escola primária do governo em Vila Cabral e uma escola secundária em Nampula. A Missão Anglicana tinha também uma escola primária juvenil em Ngoo, uma aldeia das margens do lago a 15 milhas para norte, e os católicos romanos tinham três pequenas escolas primárias juvenis, mas a sua escola primária completa mais próxima ficava em Massangulo, a 140 milhas de distância. Os habitantes do Niassa interessavam-se muito pela educação, e muitos enviavam os filhos para a Niassalândia ou para outros países, por falta de escolas adequadas na região.
} 
Em dezembro de 1963, arrancou o colonato de Nova Madeira, com famílias madeirenses; uma iniciativa do governador do distrito, apoiada pelo governador-geral de Moçambique. Surgiu inicialmente da vontade de acolher portugueses naturais da ilha da Madeira que se encontravam em Lourenço Marques sem emprego e desse modo potenciar o povoamento europeu do Niassa. Na escolha do local, a $16 \mathrm{~km}$ de Vila Cabral, pesou a boa qualidade dos solos, as possibilidades de irrigação, e o fato de já ali estar instalado por conta própria, desde 1957, o agricultor madeirense Manuel França de Lima, que ajudou no acolhimento aos patrícios que iam chegando ao colonato. Refira-se que o então governador-geral de Moçambique, Manuel Sarmento Rodrigues, já desde os seus tempos como ministro do Ultramar, defendia que o povoamento branco de Angola e Moçambique devia ser auxiliado pelo Estado de todas as maneiras possíveis.

Aceito todos os sistemas, todas as achegas, só vejo o povoamento no fim de todos os atos. Chego a subordinar-lhe tudo, como a uma ideia mestra. Puro engano. É apenas um caminho - um largo caminho - para se alcançar a grandeza una da Nação [...]. É possível que nem toda a gente se aperceba deste momento histórico, genésico, que estamos atravessando. Dos perigos que nos espreitam (Rodrigues, 1956, p. X-XI). ${ }^{9}$

Previa-se que cada colono recebesse uma casa de habitação, 100 hectares de terreno, sementes de milho, alfaias agrícolas, um subsídio mensal. À Junta Provincial do Povoamento de Moçambique (JPPM), organismo criado em 1961 no âmbito das reformas do ministro do Ultramar Adriano Moreira, cabia a assistência técnica aos povoadores, no domínio da agricultura, comercialização dos produtos e construção de caminhos e pontes até às suas propriedades. Esse trabalho foi assegurado pelo engenheiro agrónomo António Fernandes Coelho Madureira, chefe dos serviços de Agricultura e Florestas do círculo do Norte, e por um prático agrícola (a partir de 1966).

Depois do início da guerra em Moçambique, o governador de Cabo Delgado afirmaria que o escasso povoamento europeu era um mal que, no entanto, impedira que a subversão tivesse maiores consequências no terreno. ${ }^{10}$ Em seu entender, o povoamento com colonos metropolitanos não conseguiria fazer face ao avanço da Frelimo. Não obstante, no âmbito do poder central acreditou-se nas potencialidades do povoamento branco como uma componente da

\footnotetext{
${ }^{9}$ A frase em itálico é uma alusão ao contexto adverso que Portugal enfrentava com a crise de Goa (após a independência da Índia britânica em 1947), a grande vaga da descolonização em África e a crescente contestação internacional contra o colonialismo português, nomeadamente no seio da Organização das Nações Unidas. Veja-se, nomeadamente, Alexandre (2017)

${ }^{10}$ AHU, DGE-RPAD, cx. 85. Basílio Pina de Oliveira Seguro, "Povoamento no distrito de Cabo Delgado", 2.5.1967, documento enviado ao inspetor superior da Administração Ultramarina, Hortênsio de Sousa.
} 
política de segurança e defesa do território. O Terceiro Plano de Fomento (1968-1973) atribuía verbas para financiamento de povoadores já instalados e para fixação e financiamento de novos povoadores a instalar em três regiões consideradas prioritárias por razões estratégicas que tinham a ver com o avanço da Frelimo, uma das quais no distrito do Niassa (Mandimba). ${ }^{"}$ No Niassa previa-se a instalação de trezentas famílias europeias e 150 famílias africanas até o final de 1973; a concretização esteve muito aquém destes números. A aposta era contestada no seio do aparelho de Estado, dado a elevada despesa envolvida (sobretudo com o transporte e instalação inicial dos colonos) e a falta de atratividade do programa para os emigrantes portugueses que preferiam fixar-se em França e noutros destinos europeus, onde lhes eram oferecidos melhores salários e estavam sujeitos a menos riscos.

A Frelimo, criada em Dar-es-Salaam em 1962, intensificou o trabalho de mobilização e recrutamento no Niassa em 1963, especialmente em Cóbuè e na Missão Anglicana de Messumba, e as autoridades coloniais portuguesas estavam conscientes e preocupadas com a situação (Ndegue, 2009, p. 19). Em setembro de 1963, vários professores e alunos da Missão de Messumba partiram para a Tanzânia; em outubro, os régulos (chefes políticos locais) Mataca e Chitege (Cobué) enviaram cinquenta homens "evoluídos" para a Tanzânia e os cartões Frelimo começam a ser vendidos; em novembro, os portugueses perceberam que as populações dos regulados (territórios governados pelos régulos) Massange, Mataca e Chitege estavam sendo convencidas a deixar Moçambique. A percepção portuguesa era de que a adesão da população Nianja às atividades da Frelimo evoluiu rapidamente devido às fortes relações familiares com pessoas do outro lado da fronteira, na Tanzânia e no Malawi (Hipólito, 1970, p. 36).

Milton Correia (2017, p. 277) salienta que não só as populações Nianja da região ocidental do Niassa foram sensíveis às aspirações nacionalistas, também "as populações e autoridades Yao vinham sendo influenciadas pelo movimento nacionalista desenvolvido em Tanganyika e que essa influência acabou se transformando em um elemento de sensibilização das populações Yao da região oriental do Niassa" no sentido da luta de libertação de Moçambique.

Em 25 de setembro de 1964 a guerra colonial teve oficialmente início em Cabo Delgado com o ataque ao posto administrativo de Chai. Episódio idêntico teve lugar no Niassa, quando um grupo armado, comandado pelo antigo estudante da Missão Anglicana de Messumba, Daniel Polela, entrou no distrito pela fronteira norte e assaltou o posto administrativo do Cóbuè, tendo retirado depois para Likoma. No dia seguinte, outro grupo armado, comandado por Mateus Malopa, antigo professor da mesma Missão, atacou a lancha "Castor", da capitania do lago Niassa, atracada na baía de Metangula e em dezembro o posto

${ }^{11}$ As outras duas eram em Cabo Delgado (Montepuez) e Zambézia (Lioma) 
administrativo de Olivença (no norte do distrito) foi atacado (Hipólito, 1970, p. 37-38). Em janeiro de 1965, as tropas portuguesas sofreram graves baixas numa operação conduzida pela base da Frelimo em Ngombe (documento dos serviços de informação portugueses, citado por Ndegue, 2009, p. 215). Em dois anos, as atividades de guerrilha espalharam-se a todo o distrito, particularmente vulnerável, como já referi, do ponto de vista administrativo, militar e das infraestruturas de comunicação e transporte. ${ }^{12}$ Graças aos Yao, a Frelimo pôde estabelecer na Frente do Niassa um corredor de infiltração e de expansão da guerra, de importância geoestratégica, interligando a Tanzânia e o Malawi, e assegurando a comunicação política e militar entre a sua sede em Dar-es-Salaam e os comandos militares das frentes do Niassa e do centro de Moçambique (Tete, Zambézia e Manica e Sofala) (Correia, 2017, p. 236-255 e 277-278). Embora a luta armada tenha começado na região ocidental do Niassa em núcleos Nianja, o surgimento do corredor Yao, que as autoridades coloniais referiam como "estrada de Mataca", evidencia "a aliança e a unificação política das populações e autoridades do meio rural em torno do discurso de independência nacional" (Correia, 2019, p. 13;2017, p. 279).

A guerra no Niassa provocou uma fuga em massa das populações para o "mato" e para territórios limítrofes (Malawi e Tanzânia). Entre 40\% de Ajauas e 50\% de Nianjas deixaram de estar sob autoridade portuguesa. ${ }^{13}$ Em 1966 encontravam-se na ilha de Likoma cerca de três mil refugiados nianjas, quase todos da área do Cobué. Também havia refugiados em campos no sul da Tanzânia.

A partir de 1966 os aldeamentos foram encarados pelo governador do distrito do Niassa, o tenente-coronel Nuno de Melo Egídio, como estratégia de contrassubversão, para subtrair as populações à influência da Frelimo, impedir o apoio ao movimento e o seu abastecimento com géneros agrícolas; e, simultaneamente, instrumento ao serviço do desenvolvimento, capaz de acelerar o progresso económico-social das populações rurais. No vizinho distrito de Cabo Delgado, o governador coronel Basílio Seguro tinha preconizado a mesma solução em 1965, baseado no conhecimento de experiências realizadas por outras potências coloniais.

Em poucos anos, a esmagadora maioria da população ajaua e nianja que ficou no distri-

\footnotetext{
${ }^{12}$ Sobre a evolução da luta armada de libertação de Moçambique na Frente do Niassa, ver Correia (2019, p. 18-30).

${ }^{13}$ Raquel Soeiro de Brito refere que "dos 95 mil habitantes nas circunscrições de predomínio Ajaua, em 1964, em 1966/67 apenas 49 mil se mantinham sob a proteção das autoridades portuguesas, registando-se 59.800 em finais de 1968, ou seja um pouco mais de sessenta por cento da população existente quatro anos antes. Contudo, em áreas mais restritas as diferenças são cifradas em números muito maiores: por exemplo, Muembe cuja população do posto (repartida por várias aldeias ao longo do vale) rondava os 9 mil habitantes não conta ainda agora senão uns escassos 2.200 [...]. De cerca de 25 mil habitantes nianjas registados em 1964, apenas 12 mil se encontram sob controle das autoridades portuguesas [...]; isto significa que ainda metade da população anda no mato ou se encontra em países vizinhos." Relatório da campanha de trabalho de 1969 da Adjunta da Missão de Geografia Física e Humana do Ultramar Raquel Soeiro de Brito. [s.l.: s.n., 1969], fl. 2-3. Documento datilografado. Consultado no CDI-IICT (cota 13429).
} 
to do Niassa, e a entretanto capturada pelas tropas portuguesas ou regressada voluntariamente, foi aldeada. Estimava-se que 171.649 africanos estivessem aldeados em 116 aldeamentos em agosto de 1971; ;4 a 31 de agosto de 1973 eram 227.647.15 Inicialmente, os aldeamentos foram sendo construídos à medida das necessidades impostas pelo avanço da Frelimo, sem obedecer a estudo ou plano prévio norteador. Posteriormente foram produzidos alguns estudos sobre a estrutura, organização e fins que os aldeamentos deviam ter..$^{16}$

O Comando da ZIN [Zona de Intervenção Norte] difundiu regras que estabelecem o que deve ter um aldeamento para a sua defesa próxima, dentro do princípio de que o Exército não pode estar a proteger aldeamentos e de que àqueles é que se devem criar as necessárias condições de defesa, como aliás foi preconizado.

Há, até, um croquis indicando como é que os aldeamentos se devem conceber e, por ele, não é de fazer, como casos há, aldeamentos de seis quilómetros de comprimento em bicha. Do aldeamento mal concebido e mal orientado só beneficia o terrorismo. Há que controlar as populações dos aldeamentos e os seus movimentos. Há notícias de que, por vicissitudes da estruturação dos aldeamentos, os terroristas, para não serem incomodados, se acolhem já a eles abertamente e ali disfrutam de guarida segura. ${ }^{17}$

Num relatório, elaborado por um agente da Polícia Internacional de Defesa do Estado - Pide (polícia política) em funções em Cabo Delgado, apresenta-se um plano de trabalho para aldeamentos futuros. Em anexo, inclui o esquema do traçado julgado ideal para as novas aldeias com capacidade para duzentos fogos. $\mathrm{O}$ autor defende que os aldeamentos em Moçambique não devem ser cópia dos que os franceses fizeram na Argélia e os americanos no Vietnã e enfatiza que a ocupação humana só deve ocorrer havendo a garantia da disponibilização de serviços sociais, assistência religiosa e condições básicas de vida. Só assim se poderia "desenraizar as massas nativas do primitivismo em que vivem" e promover a sua subordinação exclusiva à administração portuguesa.

Nenhum aldeamento deverá ser ocupado sem que nele estejam instaladas a enfermaria, a escola, a capela, a mesquita, a área bastante para as culturas alimentares e de

\footnotetext{
${ }^{14}$ AHD, GNP, Contrassubversão. Ofício secreto do governador-geral de Moçambique para o ministro do Ultramar, 18 ago 1971.

${ }^{15}$ Ata da Reunião do Conselho de Defesa Militar do Estado de Moçambique, out. 1973, apud Souto (2007, p. 231).

${ }^{16}$ ANTT, Serviços de Centralização e Coordenação de Informação de Moçambique (daqui em diante SCCIM), n. 1638. Fernando Manuel de S. Calçada Bastos, (Subsídio) Relações humanas e política de aldeamentos como base na promoção social, Namuno [Atenção: concelho de Montepuez], 1970 (exemplar datilog. policopiado assinado pelo autor).

${ }^{17}$ ANTT, SCCIM, n.0 1639. Acta n. ${ }^{0} 16$ da Comissão de Informações, Comissão Técnica de Trabalhos, SCCIM, reunião de 19.9.1966, fls. 252 e 260 .
} 
rendimento, campo de reuniões e diversões, sistema de saneamento, e tenda ou mercado e garantido o abastecimento de água.

Para dar execução a cada uma destas necessidades, será indispensável que ele seja estudado nos seus vários aspectos, individuais e coletivos em relação aos aldeados e aos funcionários encarregados; estes na sua formação e capacidade de trabalho.

Se desejamos ativar o processo de integração na nossa administração das massas autóctones em detrimento da vida tribal, não será, certamente, destruindo-lhes esta e criando-lhes, ao mesmo tempo, problemas de ordem individual de difícil solução no seu atual estado de desenvolvimento social e mental.

Deverá organizar-se a vida do indivíduo de forma a dar-lhe em troca da sua vida isolada e sedentária no mato, mas livre, a vida na aldeia com o mínimo de perturbações e satisfazendo-lhe necessidades que aquela não lhe proporcionava. Depois de instalado e integrado no aldeamento [...] se cuidará de eliminar a sua hierarquia, começando por influências invisíveis minando o poder do régulo até à sua substituição pelo regedor funcionário do Estado com preparação que lhe proporcione o desempenho das prorrogativas adequadas. ${ }^{18}$

Um denominador comum aos aldeamentos foi a violência do processo: desde logo, o cerceamento da liberdade de movimentos, o controlo e a disciplina imposta no interior dos aldeamentos (nomeadamente, Afonso e Gomes, 2010, p. 578-579). ${ }^{19}$ As casas dos aldeamentos eram numeradas e a população identificada. O limite da maioria dos aldeamentos era feito com arame farpado e neles funcionavam sistemas de alarme e defesa; proporcionados por polícias e milícias. Não é demais frisar que a remoção das populações das suas casas e aldeias e da proximidade das suas machambas (campos de cultura) e locais sagrados também era um ato de enorme violência. Apresentado às populações sob o discurso do desenvolvimento, como um meio de garantir o seu progresso económico e social, o acesso a escolas, saúde, cantinas, estradas, assistência técnica etc., o aldeamento forçado das populações implicou um sentimento de insegurança dada a falta de apoio espiritual dos antepassados, a separação de famílias, a desautorização das autoridades tradicionais, a desestruturação da sua vida social e económica, com impactos psicológicos incalculáveis (Henriksen, 1983, p. 156).

O processo de aldeamento numa primeira fase contribuiu para o êxodo das populações, que não queriam ser aldeadas e eram aconselhadas pela Frelimo a fugir. Numa segunda fase,

\footnotetext{
${ }^{18}$ ANTT, SCCIM, n.0 1639. Relatório n.o 678/67/GAB, da PIDE - Delegação de Moçambique secreto. Distrito de Cabo Delgado. Ass.: Sugestão de construção futura de aldeamentos, 5 maio 1967, fl. 13-14.

${ }^{19}$ A afirmação de Kaúlza de Arriaga (1977, p. 212) de que "os aldeamentos eram abertos e quem os pudesse abandonar podia fazê-lo" não corresponde à realidade, devendo ser entendida como pura propaganda. As fugas ocorreriam à revelia das autoridades.
} 
a Frelimo terá mudado de estratégia, procurando a colaboração dos aldeados. Elementos da Frelimo ter-se-ão acolhido em aldeamentos, operando a partir do seu interior. As autoridades civis e militares portuguesas, confrontadas com diversos episódios desse teor, não conseguiram pôr-lhes cobro, assim como ao auxílio prestado pelos aldeados a familiares e conterrâneos que se encontravam no mato (Afonso e Gomes, 2010, p. 657).

Perante as críticas na imprensa internacional à política de aldeamentos conduzida pelas autoridades portuguesas em Moçambique, "acusada de ser uma cópia da 'falhada' experiência americana no Vietnã”, no início de 1974 os Serviços de Centralização e Coordenação de Informações de Moçambique (SCCIM) procuraram documentar-se sobre como defender a solução portuguesa. ${ }^{20}$ Além de um livro de um "autor francês sobre os aldeamentos em África"(os SCCIM põem a hipótese de se tratar de George Balandier), ${ }^{21}$ encontraram informação de que as instruções reais para as capitanias recomendavam a fixação das populações junto das principais vias de comunicação, menções ao assunto na Reforma Administrativa Ultramarina de 1933 e no programa do concurso para secretários de circunscrição, e através de uma dissertação de licenciatura defendida no Instituto Superior de Ciências Sociais e Política Ultramarina (ISCSPU, sucessor da antiga Escola Colonial, destinado à formação de quadros administrativos para o império), no ano letivo 1965-1966, a referência aos aldeamentos defendidos pelos jesuítas no Brasil no século XVI. Na referida dissertação, Alexandre Cancelas (1972, p. 133-134), que fora funcionário administrativo em Moçambique, argumentava que desde sempre os aldeamentos se tinham constituído como condição de promoção social. Referia que os aldeamentos defendidos pelos jesuítas no Brasil já visavam a transformação das mentalidades e instituições dos ameríndios e dos negros; e afirmava que o estudo mais completo realizado pelo governo português sobre a questão dos aldeamentos havia sido o projeto sobre a "organização social e económica das populações indígenas" e o parecer n. 44 do Conselho Superior do Império Colonial, de 1941, cujo relator fora Lopo Vaz de Sampaio e Melo.

Em março de 1974, o governador-geral de Moçambique, Manuel dos Santos Pimentel, solicitava ao ministro do Ultramar que lhe fosse enviado o projeto e o parecer, ou se tal não fosse possível, "uma nota ou trabalho suficientemente detalhado sobre o problema dos ‘al-

\footnotetext{
20 Sobre a génese, evolução político-institucional, funções e relações deste ramo civil da intelligence portuguesa criado em Moçambique em 1961, em consequência do início da guerra colonial em Angola, ver Araújo (2018, p. 76-166).

${ }^{21}$ Provavelmente tratava-se da obra: George Balandier, Les villages gabonais: aspects démographiques, économiques, sociologiques, projets de modernisation, Brazzaville: IEC, 1952

ACHAVA, Benedito 2018ento de novos colonosa tinha gerado um clima de mal estar e tensto (chefe de grupo Lucumues and the compar.
} 
deamentos' desde que ele se pôs [pela primeira vez] e da sua evolução através dos tempos". ${ }^{22}$ O envio do documento foi autorizado a 26 de março, sensivelmente um mês antes do golpe militar do 25 de abril na metrópole, que poria fim à ditadura e abriria caminho para o fim da guerra e do domínio colonial. Este episódio mostra que se procurava fundamentar a solução dos aldeamentos no norte de Moçambique numa reflexão e experiência históricas, embora o processo tivesse sido marcado por improvisações e por uma deficiente comunicação entre os vários graus da hierarquia do Estado, bem como entre o poder civil e militar (Afonso e Gomes, 2010, p. 578). Segundo reflexão posterior de Kaúlza de Arriaga (1977, p. 212): "as Autoridades Centrais nunca se interessaram dedicadamente pelo aldeamento".

\section{Impactos sociais}

Entre 1962 e 1964, Raquel Soeiro de Brito, ao serviço da Missão de Geografia Física e Humana do Ultramar Português, fez três campanhas de trabalho de campo no Niassa, mais especificamente na região do planalto de Vila Cabral e do lago Niassa, junto de Ajauas (Yao) e Nianjas. No relatório da primeira campanha, dava conta que os Ajauas eram muçulmanos e viviam nos planaltos, dedicando-se principalmente à cultura do milho, do feijão, da batata-doce etc. ("eram bons agricultores", afirmava a geógrafa). ${ }^{23}$ Viviam em pequenas aldeias muito coesas. Uma parte dos Nianjas também era muçulmana. Porém, os Nianjas que viviam a norte de Metangula eram em geral protestantes, devido à influência da Missão Anglicana de Messumba, instituída na década de 1880, e que lhes dispensava assistência religiosa, social e educação (até um grau mais elevado do que nas escolas das missões católicas ou nas raríssimas oficiais). Os Nianjas dedicavam-se sobretudo à pesca e cultivavam um pouco de mandioca nas terras pobres e esgotadas das margens do lago. O seu habitat era muito disperso em pequenas povoações ou em aldeias abertas. Entre os dois povos estabelecera-se uma economia complementar, trocando entre si milho e peixe. Ambos há muito participavam em migrações interterritoriais, com a Niassalândia e o Tanganica (Malawi e Tanzânia, depois da independência). Os Nianjas depois dos estudos no território vizinho muitas vezes por ali permaneciam empregando-se no comércio, nalguma indústria e até na administração. Segundo Raquel Soeiro de Brito, os Nianjas eram o grupo étnico mais desenvolvido, devido a uma educação em média mais elevada, embora as condições de vida local fossem mais difíceis. ${ }^{24}$

${ }^{22}$ Ofício de Manuel Pimentel dos Santos, governador-geral de Moçambique, para o ministro do Ultramar, datado de 9 mar. 1974. AHD, GNP, Contrassubversão.

${ }^{23}$ Raquel Soeiro de Brito, Relatório da Missão (1962), s.l.: s.n., s.d., fl.2. Documento datilografado. CDI-IICT (cota P 2104/4).

${ }^{24}$ Raquel Soeiro de Brito, Relatório da Missão (1962), fl. 6. 
Devido ao início da luta armada pela Frelimo, a geógrafa não pôde aprofundar alguns aspectos do seu estudo sobre os modos de vida e localização dos povos Nianjas e Ajauas do Niassa. No seu relatório da campanha de 1964, refere dificuldades na elaboração das plantas de aldeias mais características devido à falta de "clima humano": "o chefe Mataca, que no ano anterior tinha sido muito amável, estava 'fechado', de poucas falas, ar carrancudo e... não indicou ninguém para [a] ajudar, ao contrário também do que tinha acontecido no ano anterior". ${ }^{25}$

Em 1969, foi autorizada a regressar ao terreno para avaliar as alterações introduzidas pela guerra. Cruzando a informação que fornece nos seus relatórios com os relatórios da inspecção ordinária à sede de concelho, às circunscrições e aos postos administrativos do distrito do Niassa (1970-71), e outras fontes coevas é possível perceber o impacto do "aldeamento" na vida das populações Ajauas e Nianjas. Na zona habitada por população Ajaua foram feitos grandes aldeamentos (48 na zona anteriormente estudada por Soeiro de Brito), onde a população oscila entre mil e dois mil habitantes. No aldeamento de Malica, por exemplo, o número era muito superior: quatro mil pessoas. A 31 de abril de 1971 eram 5.359 (Chiulugo, referido como aldeamento modelo, Machomane e Nova Beira tinham mais de três mil aldeados). ${ }^{26}$

Raquel Soeiro de Brito visitou o aldeamento de Malica, perto de Vila Cabral, e provavelmente outros que funcionavam como modelo para propósitos de propaganda. Daí que afirme que em relação às aldeias tradicionais os aldeamentos são melhores porque há "em todos escolas, fontanários e salas de reunião e jogos - às vezes projetando-se filmes; nos mais importantes [numa minoria, diga-se], luz elétrica na rua principal". Lamenta não ter visto sanitários nem balneários coletivos e considera que "os novos aldeamentos são 'frios'; falta- Thes o aconchego das bonitas aldeias tradicionais envoltas por frondosas árvores de fruto e sombra e em que em cada quintal havia sempre, pelo menos, uns pés de papaia". ${ }^{27}$ À roda dos aldeamentos do planalto de Vila Cabral, num perímetro entre três e cinco quilómetros, encontravam-se os terrenos de cultura, em que se cultivava o milho e o feijão.

Reconhece que o "problema dos aldeamentos [na zona do lago, de habitat maioritariamente nianja] é mais complexo, pois a tradição fazia-os agrupar em aldeias muito esparsas, com as casas distribuídas pelos caminhos de mandioca que eram sua propriedade privada", sendo compreensível a sua maior resistência aos aldeamentos. Também o problema alimen-

\footnotetext{
${ }^{25}$ Raquel Soeiro de Brito, Relatório da Adjunta da Missão de Geografia Física e Humana do Ultramar: Campanha de 1964. Lisboa, dezembro de 1964, fl. 3. Documento datilografado. CDI-IICT (cota 11100).

${ }^{26} \mathrm{AHU}$, ISANI, Mário de Albuquerque de Castro Freiria, Relatório da inspeção ordinária ao concelho de Vila Cabral, 1971.

${ }^{27}$ Raquel Soeiro de Brito, Relatório da campanha de trabalho de 1969, fl. 3. Documento datilografado. CDI-IICT (cota 13429).
} 
tar era muito mais grave, porque as terras apenas produzem mandioca e pouca. Portanto, tinham de receber rações de milho. ${ }^{28}$

Como já referi, a construção dos aldeamentos não obedeceu a um plano previamente traçado, ao contrário do que as autoridades militares pretenderiam. Foram cometidos diversos erros básicos, fruto de precipitação e voluntarismo das autoridades administrativas. Nuns casos as autoridades civis (com ou sem ajuda da tropa) contribuíram para o estabelecimento do aldeamento com o transporte de materiais mais pesados (os troncos das árvores que constituíam o esqueleto das casas e a armação das coberturas), noutros as populações não foram ajudadas. No arquivo dos SCCIM, é possível conhecer os erros cometidos no programa de reassentamento (má escolha do local de reassentamento sem atenção a grupos étnicos e sua cultura; reassentamento de populações que viviam próximas a linhas de água em áreas em que era necessário perfurar poços), a resistência das populações (as fugas, a colaboração com a guerrilha) e os problemas de saúde que os aldeamentos também enfrentavam.

Através das atas das banjas (reuniões com as autoridades "tradicionais", presididas pela autoridade administrativa colonial) realizadas aquando da inspeção ordinária dos serviços administrativos em 1971, é possível apurar algumas das queixas verbalizadas pelos chefes de grupo de povoações. No concelho de Vila Cabral, as queixas mais comuns prendem-se com a dificuldade de obtenção de água, havendo casos em que o motor de extração se encontrava avariado (chefe do grupo Massenger, chefe do grupo Lulimire), outros em que a bomba manual não funcionava (chefe de grupo Cumacóli), outros em que o poço estava seco (chefe do grupo Matengo, chefe de grupo Chicova). Outra queixa frequente reporta-se ao fato de os funcionários dos Serviços de Agricultura os virem desalojando dos sítios onde faziam as suas machambas para ali plantarem pinheiros (chefe de grupo Lucumué e chefe de grupo Matengo) e ao esbulho das suas terras pelos colonos (chefe de grupo Chiulugo que apoiou as alegações dos restantes chefes). O chefe de grupo Cumacóli frisou que os medicamentos que mandam para o posto sanitário do aldeamento são insuficientes. ${ }^{29} \mathrm{O}$ inspector, por seu turno, destaca que a produção agrícola é feita em pequena escala, por falta de segurança em zonas mais afastadas dos aldeamentos, e o comércio estava dificultado ao máximo pela carência de transportes e estradas em condições.

Na circunscrição de Maúa, os chefes de grupo queixam-se que os trabalhadores nas fazendas dos colonos recebiam os seus salários com muitos meses de atraso e não andavam satisfeitos. O inspetor esclarece que a culpa não é dos colonos, mas do atraso da Junta

\footnotetext{
${ }^{28}$ Raquel Soeiro de Brito, Relatório da campanha de trabalho de 1969, fl. 3.

${ }^{29}$ AHU, ISANI, Mário de Albuquerque de Castro Freiria, Relatório da inspeção ordinária ao concelho de Vila Cabral, 1971, fl. $84 \mathrm{~V}$.
} 
Provincial de Povoamento. Queixam-se também de falta de posto sanitário e enfermeiro, do baixo preço do algodão, que os comerciantes não compravam a dinheiro, mas por troca de mercadorias, e da falta de pagamento a quem trabalhava nas estradas. Percebe-se ainda que decisões precipitadas da autoridade administrativa tinham gerado um clima de mal-estar entre a população de um dos chefes de grupo de Maúa, além de trabalho e despesa pública desnecessários.

Notou-se [...] um certo desentendimento relacionado com a mudança de populações do Chefe de Grupo Muhôco, da regedoria Maúa, que o Administrador da Circunscrição insensata e arbitrariamente patrocinou e que o Exmo. Sr. Governador do Distrito ao conhecê-la logo a suspendeu por razões óbvias de segurança e de economia pois a região que se ia abandonar abriria mais um grande "vazio" a caminho do já desabitado Posto de Révia e as novas terras serem impróprias para a agricultura em geral. A suspensão governamental desta desconhecida mudança não evitou, contudo, que as populações tivessem trabalhado arduamente em destroncas e nas novas palhotas, quase feitas, às dezenas. A própria Administração já tinha construído no novo e impróprio local, um Posto Sanitário e uma Escola, ambos em alvenaria e cobertura a Lusalite [revestimento em placas de fibrocimento] que agora estão inaproveitados (ênfase no original) ${ }^{30}$

Relativamente à vida dos colonos de Nova Madeira, Maniamba e Maúa a informação que conseguimos apurar é também escassa e parcelar. Dispomos de elementos sobre os colonos recrutados e desistências (através da documentação da Repartição de Povoamento e Assuntos Demográficos do Ministério do Ultramar, no AHU), ecos da falta de preparação e motivação dos colonos, mas informação sobre a vida nos colonatos é sobretudo produzida no âmbito da administração e da propaganda colonial, e como tal deve ser lida (comunicações do responsável pelo colonato de Nova Madeira, relatórios do governador e da inspecção dos serviços administrativos, reportagens no Notícias, escritas pelo jornalista madeirense radicado em Moçambique desde a juventude, Rodrigues Júnior, pequenas notícias no Boletim Geral do Ultramar etc.). O ponto de vista dos colonos é muito difícil de recuperar (a não ser através de entrevistas, mas já se vai fazendo tarde).

Nos núcleos de povoamento do distrito do Niassa o agricultor colono, vindo da metrópole com passagem paga pelo Estado, recebia um subsídio inicial para instalação (roupas e artigos de cozinha), um subsídio mensal de alimentação (1.000\$00), ${ }^{31}$ pagamento de um

\footnotetext{
${ }^{30} \mathrm{AHU}$, Isani, Mário de Albuquerque de Castro Freiria, Relatório da inspeção ordinária à circunscrição de Maúa, 1971, fl. $63-64$.

${ }^{31} \mathrm{O}$ Anuário estatístico de Moçambique não apresenta os preços médios de retalho de produtos alimentares para distrito do Niassa. Em Lourenço Marques, $1 \mathrm{~kg}$ de açúcar custava $4 \$ 80,1 \mathrm{~kg}$ de azeite $28 \$ 09,1 \mathrm{~kg}$ de batatas $3 \$ 25$, pão de trigo (unidade) $5 \$ 62$ (Moçambique, 1965, p. 354-355).
} 
salário para a construção de uma "palhota", por onde começava a instalação e a partir da qual orientaria a construção da casa definitiva, alfaias, gado, tratores em regime de aluguer, sementes, subsídios extraordinários para outros artigos necessários (bicicletas, máquinas de costura, rádios etc.). As explorações agrícolas tinham uma dimensão média de 40 hectares. O período de instalação era de um ano, estendendo-se até dois, pois só no segundo ano se podia fazer um ciclo cultural completo. Todas as receitas dos colonos davam entrada na Junta, ficando depositadas no Banco Nacional Ultramarino. ${ }^{32}$ Pelo inspetor Mário Freiria sabemos que, no início de 1971, os colonos de Nova Madeira tinham em média sob cultura 35 hectares, com predominância para o milho, embora também cultivassem feijão, batata, ervilha, grão-de-bico e algum, pouco, trigo, amendoim e soja. Os colonos dispunham de 42 tratores com grades e charruas e 28 bombas e carneiros hidráulicos para abastecimento de água e irrigação. Em casas de alvenaria viviam 46 e os restantes em casas maticadas (rebocadas com barro), estando em construção 11 casas definitivas. ${ }^{33}$

No Niassa foram instituídas normas muito rígidas, tendentes a disciplinar os colonos portugueses e a aumentar a produção, mas cujo alcance apenas se compreende dado o contexto de guerra e a falta de segurança dos povoadores portugueses e dos seus bens. Começa-se por exigir que os colonos instalados no planalto do Niassa estejam reconhecidos ao Governo do Distrito, "a quem é devida a [sua] vinda, a permanência e os trabalhos em curso para que triunf[em] e [se] faça[m] homens de bem, independentes e livres". Esse reconhecimento terá que traduzir-se numa conduta apropriada, em termos morais, no escrupuloso cumprimento do contrato com o Estado e no acatamento de uma lista longa de recomendações, que incluíam:

6.ํㅡㄹ Evitar saídas e vindas para fora da exploração, nomeadamente as vindas a Vila Cabral, sem razão de maior, orientando sempre as vindas a Vila Cabral de modo que coincidam com a primeira eúltima quinta-feira de cada mês, dia em que haverá transportes oficiais [...].

7.ำ É razão para sanções, incluindo a expulsão do colono, atitudes incorretas e desumanas junto do pessoal assalariado.

8. Estabelecer e manter uma vida familiar correta e limpa, contribuindo com o seu exemplo e boas maneiras para o engrandecimento e levantamento do meio social da região.

32 JPP (Niassa), [Normas orientadoras para a ocupação], por A. Madureira, engenheiro agrónomo responsável pelo povoamento do Niassa, Vila Cabral, 2.6.1966. AHU, DGE-RPAD, Distrito do Niassa IM 1965-1967, 84.

${ }^{33} \mathrm{AHU}$, ISANI, Mário de Albuquerque de Castro Freiria, Relatório da inspeção ordinária ao concelho de Vila Cabral, 1971, fl. 10 . 
9.ํ Guardar e preservar o melhor possível todas as colheitas, não sendo permitido [...] negociar as mesmas e dispor dos seus rendimentos sem conhecimento e autorização da JPP (Niassa), excluindo as receitas da horta familiar e aviários que se julgam ser para as miudezas caseiras. ${ }^{34}$

Esses deveres são constantemente recordados pelo responsável da JPP local, o engenheiro agrónomo António Madureira, em documentos distribuídos aos colonos, as "comunicações". Os colonos são relembrados amiúde que estão proibidos de vender animais e produtos agrícolas produzidos nas terras que lhes foram distribuídas, que têm que trabalhar e poupar, que não podem recorrer a empréstimos e vales junto dos comerciantes de Vila Cabral. São avisados que, se forem encontrados embriagados pelas ruas de Vila Cabral, serão presos durante dois dias; em caso de reincidência, serão expulsos do colonato e da província. ${ }^{35}$

As comunicações da JPP ilustram uma postura paternalista para com os colonos e um ambiente quase concentracionário. Porém, também indiciam que os colonos não respeitavam o estabelecido no contrato, estavam desmotivados, não se adaptavam ao esquema imposto e tratavam mal os trabalhadores assalariados africanos. Importa esclarecer que a formalização por escrito da condenação dos maus-tratos infligidos aos trabalhadores negros e a imposição de penalizações (chegando até à expulsão do colonato) mostra que a violência e arbitrariedade não eram práticas esporádicas nem atípicas, fruto do mau caráter de um ou outro colono. O racismo e a exploração laboral eram, antes, pilares das relações sociais decorrentes do sistema colonial. ${ }^{36}$

$\mathrm{Na}$ época a censura não permitia que as dificuldades e os insucessos dos colonos fossem noticiados. Sabemos que o fato de o colonato de Nova Madeira ser descentralizado não facilitava a disponibilização de serviços básicos, como escolas e postos de saúde, aos colonos. Há notícia de um caso de uma menina chegada ao colonato com 8 anos que aos 12 ainda não tinha ido à escola. Das 74 famílias de colonos (51 europeias - madeirenses e açorianas - e 23 africanas) instaladas no Niassa em 1971, ${ }^{37}$ as autoridades congratulavam-se publicamente por apenas três terem abandonado Nova Madeira, "um exemplo de ocupação em zona de terrorismo" (nas palavras do deputado Salústio Pires, Assembleia Nacional, 20 jan. 1967, p. 1055). Este deputado exaltou a "heroica determinação" dos colonos, que "já

\footnotetext{
34 Junta Provincial de Povoamento (Niassa), Comunicação n.0 1, 1.2.1965. AHU, DGE-RPAD, Niassa IM (1965-1967), 84.

${ }^{35}$ Comunicações n.o 2 (5 fev.1965), 3 (23 fev.1965) e 5 (30 abr.1965). AHU, DGE-RPAD, Niassa IM (1965-1967), 84.

${ }^{36}$ A propósito da discriminação racial e do trabalho forçado (vulgo "chibalo"), no sul de Moçambique, ver Penvenne (1993), nomeadamente p. 13-44 e 155-204; e Zamparoni ([2007] 2012, p. 115-177).

${ }^{37}$ AHU. Mário de Albuquerque de Castro Freiria, Relatório da inspeção ordinária ao concelho de Vila Cabral, 1971, fl. 10. 0 total de indivíduos era de 349, sendo 63 mulheres e 212 menores. No princípio de 1972 havia 83 colonos (chefes de família?) em Nova Madeira. Cf. Moçambique. Secretaria Provincial de Agricultura, Relatório síntese de atividades, 1972, Lourenço Marques, 1973, p. 141.
} 
muitas vezes [haviam sido] vítimas de ataques de bandoleiros". Sendo o colonato de Nova Madeira um povoado descentralizado a defesa tornava-se difícil, o que permitiu que colonos fossem mortos e raptados por guerrilheiros da Frelimo. Logo em junho de 1966, uma colona recém-chegada dos Açores e três filhas entre os 2 e os 6 anos incompletos foram raptadas da sua casa pela Frelimo. A população europeia terá entrado em pânico e as autoridades civis e militares não as conseguiram recuperar. Seriam resgatadas na Tanzânia pelo padre Jorge Camejo, secretário do bispo do Niassa (Nogueira, 1995, p. 51-54). ${ }^{38}$ Outros casos não tiveram desfecho feliz. Por exemplo, a ll de março de 1970 a casa de um colono madeirense foi assaltada e este, a sua mulher e o futuro genro foram mortos, e um dos filhos ficou ferido. Mesmo depois do 25 de abril de 1974 há notícia de um ataque e rapto. ${ }^{39}$

As desistências eram encaradas com enorme preocupação. O secretário provincial de Terras e Povoamento, em ofício para a repartição de Povoamento e Assuntos Demográficos, explicava que a esposa de um colono tinha manifestado "sintomas de inadaptação ao meio e reação ansiosa” logo após a instalação e salientava a necessidade de haver critérios mais exigentes no recrutamento de novos colonos.

Dado que a situação verificada, além de constituir um pesado encargo para o Estado com passagens de vinda e regresso para todo o agregado familiar [2 adultos e 6 filhos menores de 7 anos], constitui ainda um precedente encorajador em favor de outros colonos menos apegados ao trabalho da terra ou descontentes como o meio - o que se encara com muita apreensão - tenho a honra de expor este assunto a V. Exa., tendo em vista a melhor seleção de futuros colonos para novos contingentes a embarcar para esta Província. ${ }^{40}$

Uma solução para assegurar o rendimento dos colonos sem os pôr em perigo surgiu de forma imprevista. Vítor Silva, piloto nos Transportes Aéreos do Niassa (1968-1972), através do livro History of the Universities' Mission to Central Africa, que lhe foi oferecido pelo padre Paul da Missão de Messumba, soube que num relato de viagem de Zanzibar ao lago Niassa um

\footnotetext{
${ }^{38}$ Nogueira (1995, p. 54) recorda que "A aventura foi silenciada na imprensa moçambicana, mas teve eco na metrópole, com honras de primeira página e fotografia no Diário de Notícias", de 27 de março de 1967. Jornalistas da Alemanha e África do Sul também foram entrevistar o "herói", relatando nas suas reportagens "um gesto de paz no meio da guerra, digno de um filme." O jornal católico Novidades, de 7 de fevereiro de 1967, e o semanário Reconquista, de Castelo Branco, de 9 de abril de 1967, noticiaram o episódio. Veja-se o depoimento na primeira pessoa em "Padre Jorge Camejo: as peripécias de uma vida com história”, 22 de abril de 2007. Disponível em: <http://correiodecoimbra.blogspot.com/2007_04_22_ archive.html>. Acesso em: 12 mar. 2020.

39 Segundo Lusitano (1974, p. 78), o Diário de Notícias, de 2 de setembro de 1974, dava conta de um ataque ao colonato de Nova Madeira e do rapto de uma jovem de 18 anos e de quatro crianças de uma casa de colonos brancos.

${ }^{40}$ AHU. MU, DGE-RPAD, ofício do secretário provincial de Terras e Povoamento, para a DGE-RPAD, datado de Lourenço Marques, 8 jul. 1971.
} 
explorador missionário do século XIX referiu que nos planaltos do Niassa abundavam pujantes gladíolos selvagens. O piloto contactou o engenheiro Madureira, dos Serviços de Agricultura, e este mostrou-se interessado em experimentar a cultura de gladíolos no colonato de Nova Madeira, que enfrentava "enormes dificuldades resultantes da guerrilha e das minas". ${ }^{41}$ Muitas das colonas, oriundas da ilha da Madeira, já tinham experiência em floricultura e a produção dos gladíolos podia fazer-se junto às habitações, evitando deslocações arriscadas. Acresce que podia ser escoada por via aérea, numa região onde continuavam a escassear as comunicações terrestres rápidas e seguras. Foram distribuídos aos colonos bolbos importados da Holanda e Vítor Silva encarregou-se de colocar as flores em Nampula, na Beira e Lourenço Marques.

O colonato de Mandimba, erigido perto da fronteira com o Malawi, ao contrário do colonato de Nova Madeira, tinha as casas agrupadas para oferecer uma postura defensiva, e dispunha de serviços básicos, como uma escola, posto de saúde e um centro social, mas os campos de cultivo ficam muito distantes do colonato, cerca de $10 \mathrm{~km}$ (Jundanian, 1974). Foi também afectado por sequestros (o primeiro em meados de 1966) e mortes; uma explosão de minas terrestres matou várias pessoas em outubro de 1971, no mesmo dia em que chegaram cerca de vinte famílias açorianas. O ano agrícola 1971-1972 foi considerado "deveras mau" para os 96 colonos instalados em Mandimba, ${ }^{42}$ que, além disso, se queixavam das deficientes condições de acolhimento e de defesa.

É, portanto, compreensível que o ânimo dos colonos fosse abalado pela insegurança, pelo medo e pela tensão racial, não obstante toda a propaganda sobre as potencialidades do Niassa para o povoamento europeu e produção agrícola diversificada e toda a exaltação nacionalista da capacidade colonizadora portuguesa.

Em 1973, o Secretariado Nacional de Emigração faz um balanço desapaixonado da sua participação no recrutamento de colonos metropolitanos para núcleos de povoamento dirigido nas províncias ultramarinas. Refere o reduzido número de inscrições, mesmo nas zonas rurais com grande densidade demográfica, o elevado absentismo por parte dos inscritos aquando da convocação e a acentuada desistência antes do embarque. Perante as críticas de muitos colonos instalados em Moçambique, ${ }^{43}$ sugere que a JPPM passe a carac-

\footnotetext{
${ }^{41}$ Vítor Silva, "Gladíolos em Vila Cabral, agora Lichinga”, postado por Luisa Hingá, 25 out. 2006. Disponível em: <http:// voandoemmozambique.blogspot.com/2006/10/101-gladiolos-em-vila-cabral-agora.html>. Acesso em: 5 nov. 2019.

${ }^{42}$ Moçambique. Secretaria Provincial de Agricultura, Relatório sintese de atividades - 1972, Lourenço Marques, 1973, p. 141.

${ }^{43}$ Ver Informação n. 122/RPAD/72, da Repartição de Povoamento e Assuntos Demográficos, sobre "Núcleos de povoamento agrário da Junta Provincial de Povoamento de Moçambique - Dificuldades surgidas com a instalação de colonos", de 30 set. 1972; Informação n. 117/RPAD/72 sobre Reclamação de colonos dos núcleos de Mandimba. AHU, DGE-RPAD, Despacho do Presidente do Conselho de 21 de abril de 1972, 143; cartas de colonos açorianos denunciando as más condições de acolhimento nos núcleos de povoamento agrário, anexas à Informação, s.d. [1973], do Secretariado Nacional de Emigração. DGACCP-MNE, Arquivo JE/SNE, 9.3/O2.
} 
terizar convenientemente a oferta (exata situação geográfica dos núcleos, área e localização de cada parcela, natureza das culturas a desenvolver, características da habitação, encargos suportados pelo Estado, financiamento estatal a título reembolsável, apoio técnico, médico, social e religioso), com vista a não se repetir o fornecimento de informações imprecisas ou inexatas aos colonos nem o incumprimento das obrigações do Estado para com eles (falta de condições de habitabilidade das instalações destinadas aos colonos, redução na área das parcelas entregues, falta de pagamento dos subsídios etc.).

\section{Considerações finais}

Idealizados como barreira à subversão e polos de desenvolvimento nos meios rurais, aldeamentos e colonatos não chegaram a constituir zonas tampão à infiltração da guerrilha nem a conquistar "mentes e corações". Na prática, os aldeamentos não garantiram melhores condições de vida aos autóctones. Desestruturaram a vida das comunidades locais de forma irreversível (aliás, a "destruição da vida tribal" era um objetivo plenamente assumido), revelando-se incapazes de substituir a organização social e económica anterior por um novo sistema mais eficaz (Jundanian, 1974, p. 534-540). Não é possível antever uma política social em prol das populações aldeadas. Mesmo a expansão da rede escolar e sanitária em número de edifícios para tal construídos não era acompanhada pela disponibilização correspondente de pessoal com as necessárias habilitações. Por seu turno, os colonatos não tiveram capacidade para atrair um número significativo de potenciais migrantes; apenas os mais pobres e menos preparados se apresentavam (ao engano, verificariam depois). A seleção foi cada vez menos rigorosa, permitindo o recrutamento de chefes de família analfabetos e sem prática agrícola prévia. Se, nalguns casos, os colonatos contribuíram para uma melhoria das condições de vida de portugueses da metrópole, provavelmente essa melhoria não foi suficiente para suplementar o isolamento e a insegurança numa zona de guerrilha. Aquando da independência de Moçambique, os colonos de Nova Madeira e de outros pequenos núcleos de colonização portuguesa regressaram à antiga metrópole. E os 227.647 indivíduos (maioritariamente ajauas e nianjas) aldeados nos 154 aldeamentos existentes no Niassa nas vésperas da independência (números de 31 de agosto de 1973)? Como viveram a transição de soberania?

Em trabalho futuro, interessa perceber como o Estado moçambicano no pós-independência lidou com a realidade dos aldeamentos no Niassa e a integrou na sua política de desenvolvimento de matriz marxista-leninista, nas chamadas aldeias comunais. Essa transição já foi estudada para o caso de Tete (Coelho, 1993). Recentemente, Benedito Machava (2018) estudou a operação produção que, em nome de uma moral revolucionária contra os vícios urbanos e pelo progresso pelo trabalho, à revelia da escolha autónoma de cada indivíduo, enviou para o Niassa os chamados "improdutivos" das cidades (desempregados, prostitutas, 
vadios etc., mas também pessoas que não tinham os documentos consigo quando eram alvo de uma rusga (diligência policial), tendo afetado entre cinquenta a cem mil pessoas de Maputo e da Beira, forçadas a ir trabalhar para o mato na produção de géneros alimentares que escasseavam nos centros urbanos. Machava não faz referência ao reaproveitamento de aldeamentos coloniais para o estabelecimento dos campos de reeducação, mas pelo menos os campos de reeducação de Unuango e Revia foram estabelecidos em locais onde haviam existido aldeamentos. O historiador moçambicano demonstra que em vez de espaços de reforma social e crescimento económico foram os campos de reeducação espaços de negligência e abandono social. Essa situação somou-se e aprofundou a desestruturação social já em curso na região do Niassa nos últimos anos do colonialismo, como se viu neste artigo.

\section{Referências}

AFONSO, Aniceto; GOMES; Carlos de Matos (coord.). Os anos da guerra colonial (1961-1974). Matosinhos: QuidNovi, 2010.

ALEXANDRE, Valentim. Contra o vento: Portugal, o império e a maré anticolonial, 1945-1960. Lisboa: Temas \& Debates, 2017.

ARAÚJO, Sandra Marisa da Silva Carlos. Um império de previsões: os Serviços de Centralização e Coordenação de Informações de Moçambique e a Governança Colonial do Islão (1961-1974). Tese (Doutorado em Antropologia), Universidade Nova de Lisboa. Lisboa, 2018.

ARRIAGA, Kaúlza de. Moçambique. In: CUNHA, J. da Luz; ARRIAGA, Kaúlza de; RODRIGUES, Bethencourt; MARQUES, Silvino Silvério. África: a vitória traída. Lisboa: Editorial Intervenção, 1977, p. 185-249.

BALANDIER, George. Les villages gabonais: aspects démographiques, économiques, sociologiques, projets de modernisation. Brazzaville: IEC, 1952.

CANCELAS, Alexandre. Contributo para uma política social moçambicana. Braga: Pax, 1972.

CASTELO, Cláudia. Passagens para África: o povoamento de Angola e Moçambique com naturais da metrópole (19201974). Porto: Afrontamento, 2007.

CASTELO, Cláudia. Reproducing Portuguese villages in Africa: agricultural science, ideology and empire. Journal of Southern African Studies. v.42, n.2, p. 267-281, 2016.

COELHO, João Paulo Borges. O início da luta armada em Tete, 1968-1969: a primeira fase da guerra e a reacção colonial. Maputo: Arquivo Histórico de Moçambique, 1989.

COELHO, João Paulo Borges. Protected villages and comunal villages in the Mozambican province of Tete (1968-1982): a history of State resettlement policies, development and war. Tese (Doutorado em História), University of Bradford. Bradford, UK, 1993.

COGHE, Samuël. Population politics in the tropics: demography, health and colonial rule in Portuguese Angola, 1890s-1940s. Tese (Doutorado em História), Instituto Universitário Europeu. Florença, 2014.

COGHE, Samuël. Reordering colonial society: model villages and social planning in rural Angola, 1920-1945. Journal of Contemporary History. v. 52, n. 1, p. 16-44, 2017.

CORREIA, Milton Marcial Meque. Os Yao e o contexto da luta armada de independência nacional de Moçambique (1964-1974). Tese (Doutorado em História Social), Universidade de São Paulo. São Paulo, 2017.

CORREIA, Milton Marcial Meque. História e textualização: a historiografia da frente do Niassa (Mo- 
çambique) 1964-1974. História (São Paulo). n. 178, a09417, 2019. Acesso em: 13 maio 2020. DOI: 10.11606/issn.2316-9141.rh.2019.141770.

DE L'ESTOILE, Benoît. Enquêter en "situation coloniale”. Cahiers d'Études Africaines [Em linha]. n. 228, 2017. Colocado em linha 1 dez. 2019. Acesso em: 2 jan. 2020. DOI: 10.4000/etudesafricaines.21565.

DIREITO, Bárbara. Políticas coloniais de terras em Moçambique: o caso de Manica e Sofala sob a Companhia de Moçambique, 1892-1942. Tese (Doutorado em História), Universidade de Lisboa. Lisboa, 2013.

DIREITO, Bárbara. Terra e africanos no pensamento colonial português, c.1920-c.1945. Análise Social. v. XLIX, n. 213, p. 768-793, 2014.

FEICHTINGER, Moritz. 'A great reformatory': social planning and strategic resettlement in Late Colonial Kenya and Algeria, 1952-1963. Journal of Contemporary History. v. 52, n.1, p. 45-72, 2017.

GOUROU, Pierre. Une paysannerie africaine au milieu du Xxe siècle: les Kikuyu et la crise Mau-Mau. Cahiers d'Outre-mer, v. 28, p. 317-341, 1954. DOI: https:// doi.org/10.3406/caoum.1954.1928.

HENRIKSEN, Thomas H. Revolution and counterrevolution: Mozambique's War of Independence, 1964-1974. London: Greenwood, 1983.

HIPÓLITO, Abel Barroso. A pacificação do Niassa: um caso concreto de contra-guerrilha. Lisboa: Ed. Autor, 1970.

JERÓNIMO, Miguel Bandeira; DORES, Hugo. On the "efficiency" of civilization: politics, religion and the native settlement in Portuguese Africa in the 1940s. Portuguese Studies Review. v. 25, n. 1, p. 179-203, 2017.

JUNDANIAN, Brendan F. Resettlement programs: counter insurgency in Mozambique. Comparative Politics. v. 6, n. 4, p. 519-540, 1974.
LUSITANO, Prudêncio, Portugal y el presente. Madrid: Cunillera, 1974.

MACHAVA, Benedito. The morality of revolution: urban cleanup campaigns, reeducation camps, and citizenship in Socialist Mozambique (1974-1988). PhD, University of Michigan. AnnArbor, 2018.

MATINE, Manuel Henriques. A integração de famílias autóctones no colonato do Limpopo em Moçambique, 1959-1977. Dissertação (Mestrado em História), Universidade Federal Fluminense. Niterói, 2015.

MEDEIROS, Eduardo da Conceição. História de Cabo Delgado e do Niassa (c.1836-1929). Maputo: [imp. Central Impressora], 1997.

MOÇAMBIQUE. Direção Provincial dos Serviços de Estatística. Moçambique. Anuário estatístico. Lourenço Marques: Imprensa Nacional, 1965.

NDEGUE, David Francisco Xadreque. A luta de libertação na frente do Niassa, v. 1. Maputo: JV Editores, 2009. [2v.]

NOGUEIRA, Eurico Dias. Episódios da minha missão em África. Braga: [s.n.], 1995.

PAUL, John. Mozambique: memoirs of a revolution. Harmondsworth: Penguin, 1975.

PENVENNE, Jeanne Marie. Trabalhadores de Lourenço Marques (1870-1974). Maputo: Arquivo Histórico de Moçambique, 1993.

RODRIGUES, Manuel Maria Sarmento Rodrigues. Unidade da Nação portuguesa, v. 1. Lisboa: AGU, 1956.

SOUTO, Amélia Neves. Caetano e o ocaso do "Império": administração e guerra colonial em Moçambique durante o Marcelismo (1968-1974). Porto: Afrontamento, 2007.

ZAMPARONI, Valdemir. De escravo a cozinheiro: colonialismo e racismo em Moçambique. 2. ed. Salvador: EdUFBA/Ceao, [2007] 2012. 